\title{
The Politics of Curiosity
}

\author{
Eva-Maria Swidler
}

\section{Introduction}

Coming home a few months ago from yet another frustrating day of teaching, I had a sudden epiphany that crystallized my swirling emotions: curiosity is political. The absence, presence, cultivation, and extirpation of curiosity are all political tools to be wielded, yielding almost unimaginable power. Curiosity is also an outcome, a social construction, that has ubiquitous political consequences.

Although psychologists agree that curiosity is a drive that emerges from some internal (or intrinsic, in the terms they favor) place, it is also well-known that curiosity can be reduced, shaped, altered, or eliminated by surroundings. The politics of curiosity are exactly located in the question of which aspects of curiosity are internal and which are external and in the tensions and tug of war between those locations, and in the morality of our inevitable participation and intervention in those dynamics. What kinds of curiosity might be said to be "natural"? Should those natural curiosities be suppressed, allowed, or encouraged to flourish? What kinds of curiosity are socially created? What social forces, dastardly or ethical, are brought to bear on curiosity, how do they work, and what are their results? What should we do about those forces? What are the social and individual consequences of different kinds of curiosity, and therefore what is our responsibility regarding the cultivation or extirpation of those curiosities? The list of essential questions goes on almost infinitely.

As a society, our most common conversations about curiosity seem to treat it as an entirely intrinsic trait without a social side; we shake our heads at curiosity's absence and attribute a lack of it to a personal character flaw. But as John Dewey observed, "Curiosity is not an accidental isolated possession," whether virtuous or sinful. ${ }^{1}$ It seems important, therefore, to open this essay by arguing against this understanding of curiosity as an individual responsibility and to show instead that the contemporary social dynamics that militate against curiosity are many.

Curiosity is a self-initiated urge that is, by definition, satisfied by an individual's own observations and own actions and deemed satisfied by a person's own judgment, like an itch needing to be scratched. Curiosity cannot be commanded and disappears under the coercion that is the condition common to contemporary workers and students alike. As an internal condition, curiosity is specifically not oriented towards, nor encouraged by, extrinsic rewards such as status, grades, or recognition. In fact, as a guileless and self-exposing phenomenon, it most often withers when exposed to the glare of measurement, judgment, and comparison. Yet these metrics and dynamics are now considered the gold standard of the workplace, education, and increasingly society in general.

Curiosity also suffers as a "knowledge emotion" or mood state that evaporates not just under the particular scrutiny of being evaluated, but in situations of generalized insecurity and anxiety. Anxiety is the mental condition that the Institute for Precarious Studies has very plausibly 
asserted as the zeitgeist of the last (neoliberal) forty years. ${ }^{2}$ To be curious requires a comfort with not-knowing, with uncertainty, and with ambiguity, and therefore requires a deep security in the sense of self, a center of gravity that keeps us grounded while being open to questioning our knowledge. The sense of security and self-possession that curiosity is built on is surely not cultivated by our times.

Finally, although an intimate experience, the emotional aspects of curiosity, as with so many other phenomena of political import today, have been ignored to the detriment of understanding. Perhaps the emotional facet of reality has been sullied for some by an association with mid$20^{\text {th }}$ century psychoanalysis and Freudianism; in many radical circles, it is received as superficial and almost petty to talk about the emotional. Thinking of an experience as an emotion locates it in the belittled, disparaged part of the Cartesian binaries that rule intellectual life and common cultural sense: female/personal/frivolous versus male/public/consequential. Calling a phenomenon psychological rather than emotional might be one way to frame it as worthy of scientific investigation. But we must deal with emotion as such if we are to deal with people. Emotions are intimate and yet they are connected to the rest of the world, and the same goes for curiosity.

Curiosity is fundamentally built on self-possession, security, and intellectual openness because it is built on a potential willingness to engage and accept the unknown. We, on the other hand, live in an unstable global moment of intense competition and maximizing social and economic hierarchy, in which populations flounder in a resulting stew of fear, anger, anxiety, alienation, and even shame. In short, the economically and socially polarized, competitive, precarious, defensive, surveilled, judged, aggressive cultural bath we swim in makes a healthy curiosity almost impossible. And in fact, we all know intuitively, with just a moment's reflection, that defensive people, aggressive people, or despairing people are only curious despite themselves. It is obvious that our moment's zeitgeist is not conducive to curiosity. ${ }^{3}$ And all the while that curiosity is being displaced by free-floating cultural anxiety, the scales are even further tilted as curiosity is being actively squelched as a threat by those in power and actively suppressed in the self as a form of self-defense by those under cultural attack.

But simultaneously, curiosity about other places, other people, other minds, other beings, is necessary for our moral health and for our imagination of an alternate, better future, a hope for what might be. We find ourselves in a classic catch-22: to build and maintain alternative politics, communities, and social worlds we need to pursue a deep curiosity about other people, other beings, and other ways of living, but in order to make room for this curiosity in our society, we need to make fundamental social changes that allow people the conditions for an unencumbered, healthy curiosity.

Although curiosity has been long neglected as a topic of study, it behooves students of capitalism to examine it, to see why it thrives and why it withers, to imagine why curiosity might be withheld as a means of resisting exploitation and subjugation, and to ponder how a moral curiosity might be protected and nurtured.

Recognizing curiosity as necessary for creating new solidarities and political movements, this exploratory essay specifically considers the social and political roots as well as consequences of both curiosity and incuriosity, apathy, and ignorance, including such topics as willful apathy as cultural resistance and self-defense, ignorance as an ethical choice, incuriosity as arrogance, and socially generalized anxiety and the shrinking of curiosity.

\section{The State of Curiosity Studies}

Curiosity, simultaneously an intellectual and an emotional phenomenon, is surprisingly unstudied, even while it is pivotal for not only activists but also cultural critics and educators to understand. Most citations on curiosity are to be found in the fields of psychology (and its more scientifically garbed allies such as neuroscience) and education, with a healthy presence in 
the world of business; philosophy has a few entries as well. ${ }^{4}$ That teachers are concerned with curiosity is not surprising; although an excited curiosity is disruptive to the classroom and often squelched, without any curiosity at all, teachers face an almost insurmountable climb towards engaging students. That the business world is concerned with curiosity might be a bit more surprising at first glance. As frequent purveyors of a mythology of the worth of restless ingenuity and entrepreneurial inquisitiveness, the corporate attraction to the topic might make sense, but more important, perhaps, is that the world of capital is confronting what Guillaume Paoli called a "falling rate of motivation" and is looking to curiosity as a means of boosting it. ${ }^{5}$

In cultural studies, history, and the social sciences of anthropology, sociology, and political science there is little to no literature on curiosity to be found. This absence seems deeply problematic. Students of society hold unquestioningly that social structures and cultures, and our particular positions in those systems, frame and shape our thought patterns. But how do our everyday surroundings get translated into our internal worldviews and understandings? Analyses of cultural hegemony, dominant paradigms, master narratives, public discourses-all these are necessary and important. But too often they exist in a conceptual layer floating atop the level of individual people, connected to real humans only by a black box. For instance, just how is it that girls grow up scared of math? We might talk in sociology about the process of socialization-what words are said or avoided or what smiles are given or withheld--but how do those messages hit home? What do they make girls feel, and how does that new internal reality, whether mental or emotional, then perpetuate the messages? Unless we think of humans as mirrors rather than beings, or subscribe to the most primitive behaviorist or Pavlovian models in which people acquire automatic physical reactions to stimuli, we need to imagine how the inner lives of people-their understandings, fears, visions--are inscribed by social forces to produce patterned results.

As an emotion, curiosity (and the lack of it) would seem to be a key vehicle to examine, one necessary step in tracing just how society makes its way into our minds and becomes part of our intimate, individual self. Curiosities filter and direct our experiences, memories, and attention. In the most concrete and practical sense, how is it, for instance, that we can grow up in a world composed in the majority of women and yet know so little about their lives? Because we are not paying attention. We are not curious about them. The way in which sexism has been admitted to our mind is via the emotions of incuriosity and boredom. And on the other hand, what do we need if we want to bring issues into the public concern? We need public curiosity about them. The social sciences need to reckon with curiosity. ${ }^{6}$

It has been clear to the left for a long time that the contours of knowledge are politically drawn: who knows what, how they come to know it, why they care to know it, how well they know it, from what point of view they know it, are all acknowledged to be realities created by social formations and social position." Already in 1934, Upton Sinclair remarked that "(i)t is difficult to get a man to understand something, when his salary depends on his not understanding it," making a direct case for what we would now call a standpoint theory of ignorance. ${ }^{8}$ In recent years an increased interest in the politics of ignorance, as well as knowledge, has begun to take shape; agnotology, as the philosophical study of ignorance is named, builds connections among politics, psychology, and public memory to describe a process of the social construction of ignorance that mirrors the social construction of knowledge.' What people don't know, why they don't know it, and why they (in some instances, at least) don't care to know it can now be pursued as areas of active inquiry. In other words, we recognize that ignorance is often not a result of a simple lack of information, but is instead a state that is actively created and defended. Although the newly coined term of agnotology is still unfamiliar (and perhaps trendy) in academic circles, we should pause here to observe that Sinclair's quote shows us that the basic insight that the field is based on, (that ignorance can serve power), is actually a long-standing and frequent observation of the powerless.

Unfortunately, neither epistemology nor agnotology has engaged significantly with the idea of curiosity, which is, after all, a conduit of knowledge creation, the means by which the mind is engaged both to know and to ignore, the mechanism (although a mechanistic word is 
uncomfortable) by which society's messages might make their way into our inner landscape. Curiosity as a concept and a phenomenon appears to be almost entirely ignored by the liberal arts. Only in a culture with such a gaping hole could it be possible to have an "epiphany" of what should be the entirely obvious insight that curiosity is political.

\section{What is Curiosity and Why Should We Care?}

Curiosity is something of a catch-all term in English; despite its almost universally positive modern connotations in our part of the world, at least among the higher classes, it is clearly not necessarily or automatically an unmitigated good. Curiosity can also describe phenomena that occupy the more neutral ground of mere diversion or distraction--what we often term idle or aimless curiosity--or perhaps of weakness or indulgence, as it was more commonly held to be in the American and European past: "curiosity killed the cat." An active refusal of certain curiosities can be a moral choice, as in a lack of curiosity about how to create a neutron bomb or how to best torture people. Refusing to be curious can be a choice of respect, maintaining privacy or dignity by looking aside, either literally or metaphorically. Curiosity itself can represent a thirst for power. Think of the unslakeable thirst sort of curiosity of nineteenth-century imperialists and Victorian memento seekers, seeking knowledge as a form of control, or of the greedy, entrepreneurial curiosity of prospectors of every sort. Thorstein Veblen called this kind of curiosity "pecuniary curiosity," and it has been recently labeled "neoliberal curiosity" in its contemporary incarnation. ${ }^{10}$

However, curiosity of a certain kind is also considered to be a necessary foundation of morality. Carl Goldberg proposes that conscience cannot function without curiosity. Pointing out that curiosity requires the capacity to suspend judgment, the subjection of your own knowledge and beliefs to doubt, and a willingness to ask questions, Goldberg argues that the conscience also requires the suspension of certainty in order to answer the question "What is right?" For Goldberg, this moral question is one that cannot be answered without curiosity's essential elements of inquiry and reflection, in direct opposition to dogmatic thinking. ${ }^{11}$

Perhaps we can characterize a desirable curiosity, a moral curiosity, as a curiosity based not on accruing power nor on diversion, but on respect for whatever or whomever one is curious about. Curiosity as a personal trait is a significant predictor of so-called emotional intelligence, or a grasp of and respect for other minds. ${ }^{12}$ Cynthia Enloe, writing The Curious Feminist: Searching for Women in a New Age of Empire, characterizes taking women and their lives seriously as "having curiosity" about women. This kind of respectful curiosity engages with other realities and other existences as valuable on their own terms, not as instruments for us.

Curiosity has a moral dimension that is not only personal but social, as well. Without a desire to know about the world, we will never want to change it, nor know how to begin that project. Without a desire to know about other ways of being, we will never build community, solidarity, or a new reality. While support for active incuriosity and ignorance has important moral standing in some contexts, as we'll see below, as teachers, activists, or concerned citizens we must also advocate for the political and moral value of certain kinds of curiosity, curiosity which, in the words of Foucault, "evokes the care one takes of what exists and what might exist." 13 Progressive educator William Heard Kilpatrick described morality as being ready, willing, and able to assess and take responsibility for the consequences of your behavior. ${ }^{14}$ We can see, therefore, that curiosity in a deep sense, the sense of alertness and attention to care for the surrounding world, is necessary to make moral choices.

\section{Curiosity and the School}

The molding of curiosity begins at birth. While there are precious few characteristics innate in humans, curiosity is one of them. Yet it was quickly obvious to me years ago as a new mother 
that as children grow up in our society, they progressively lose curiosity, yielding a remarkably incurious adult population. While the more individual and particular forces of family dynamics and parental styles obviously shape curiosity, for most children the institutional impacts of daycare and school are behind a transformation from sparkling and delighted four-year-olds into dull and sullen children only a few years later, causing many parents to wonder whether the fairies have stolen their child.

The flattening of free-ranging curiosity in schools has been the subject of complaint for centuries. William Blake's 1789 poem “The School Boy” continues to describe the reality of children today.

\footnotetext{
"But to go to school in a summer morn,-

O it drives all joy away!

Under a cruel eye outworn,

The little ones spend the day

In sighing and dismay.
}

\section{Ah then at times I drooping sit, \\ And spend many an anxious hour; \\ Nor in my book can I take delight, \\ Nor sit in learning's bower, \\ Worn through with dreary shower.}

Our culture seems schizophrenic about children and curiosity. While trumpeting the value of curiosity for pupils and adults alike, (lists of how to improve and cultivate your curiosity abound online), actually curious children, those who remain entranced with their work when the class bell rings or who can't stop looking out the window during class, are punished.

But kindergarten and the lower elementary grades did use to be relatively free form in spirit and design, leaving learning by rote and a strong concern for standards to the later years, and sociologists and psychologists pegged somewhere around $4^{\text {th }}$ grade as the time when kids lost curiosity and when resentment and ennui overtook a joyful love of novelty and exploration. Yet even back in the mid-1980s, when nursery schools prioritized play, a study of preschoolers found that the average number of questions the children asked went from 26 per hour while at home to 2 per hour while in preschool. ${ }^{15}$ Now, however, we have "schools" even for toddlers that rehearse them in phonics. Not surprisingly, today's children, subjected to planned curricula as early as nursery school and crushed by report cards with grades as tender kindergarteners, are reported to be losing interest in school as early as first grade. ${ }^{16}$

While standardized testing, overcrowding, and underfunding undoubtedly have particularly toxic effects on the pursuit of inquiry in classrooms, the "anaesthetizing of curiosity", in Paolo Freire's phrase, occurs in any conventional educational institution. ${ }^{17}$ As researcher H. I. Day said, "To expect teachers who are trained to lead to get out of the way while students work off their curiosity is unreasonable." 18 In her book The Hungry Mind, Susan Engle devotes an entire chapter entitled "Curiosity Goes to School" to concretely describe how even the warmest, bestintentioned teachers who provide abundant hands-on learning situations kill curiosity in the quest to stay "on task" and cover the required material. ${ }^{19}$

Naturally, institutional imperatives such as grades, the ranking and sorting of students, and assessments of performance undermine the secure sense of self and the willingness to be vulnerable that are necessary for the flowering of curiosity. Engle further elaborates that uncertainty is key to learning; being shown how something works shrinks curiosity. Yet teachers are expected to structure their classrooms to transmit certainties and cultivate mastery over content as core tasks, rather than fostering exploration and uncertainty. ${ }^{20}$

Since the late 1960s, educational theorists have examined the hidden curriculum, the unspoken, inarticulate, or inexplicit lessons imparted by schools: that science is a separate subject 
from history and art, that obedience will be rewarded, that learning can be quantified. Arguably, part of the hidden curriculum is the squelching of curiosity. Is that steamrolling of curiosity an actively conceived purpose of school, or just an incidental byproduct of other dynamics? In his essay "The Masked Philosopher" Foucault described curiosity as a dangerous "casualness in regard to the traditional hierarchies of the important and the essential", and many critics over the years, from Pippi Longstocking to Charles Dickens, John Taylor Gatto, and John Holt have accused the educational guardians of the status quo of eagerly stamping out curiosity in order to enforce obedience. ${ }^{21}$

Ivan Illich terms teachers a fundamentally "disabling profession", a category of people who, in ostensibly seeking to help others, actually try to ensure that people cannot learn without them. Illich says that far-reaching monopolies in contemporary society (read "denial of access to the means of production") deprive the environment of the features needed to subsist outside the market economy, thereby ensuring that people cannot create their own use-values but must try to meet their needs by means of exchange values. In calling education a dominating and a disabling profession, he says that as a group, educators insert themselves into learning, so that "( $t$ )he longer each person is in the grip of education, the less time and inclination he has for browsing and surprise." In other words, for Illich, educators spend time purposefully suppressing curiosity so that learning cannot and/or will not take place autonomously, outside of schools, or away from professional supervision. ${ }^{22}$

Incuriosity is a passive state, while having curiosity is active and implies a confidence that the curiosity can be satisfied. A curious person believes that they have those mental capacities to investigate and learn that are needed to assuage their curiosity. If and when someone comes to believe that it is impossible to figure things out, they cease to be curious and retreat instead to passive disinterest. By inserting themselves between you and anything you want to learn, as Illich put it, "educators" teach the implicit lesson that you are unable to learn anything without them. Your curiosity is of no avail, it will lead you astray and strew your path with red herrings. Just sit back and let the experts teach you.

In fact, as Matthew Crawford wrote, the spirit of inquiry is allied with "a desire to be master of one's own stuff. It is the prideful basis of self-reliance." Self-reliance is of course, entirely uncapitalist in both its inspiration and in its reality, focused as it is on the goals of self-sufficiency and dignity. As a trait reliant on autonomy and self-direction, curiosity is inherently resistant to authority, including that of teachers. ${ }^{23}$

Or perhaps the deadening of intellectual quests in schools is not purposeful, but merely results from the pursuit of other agendas? In this understanding, curiosity might represent to administrators and testers a failure to think in the capitalist terms of calculated opportunity costs. Curiosity would be seen as an instance of engaging in impractical and wasteful woolgathering rather than pursuing a goal-oriented task completion. Needless curiosity then becomes an obstacle to the smooth instruction in vocational skills or the imbuing of patriotism that could be taking place efficiently, instead of wasting time wondering about the unsale-able. We can debate what mix of conscious intention and collateral damage might be crushing wonder and wondering in schools, but there's no denying the essential reality in those buildings.

Students quickly learn to return the favor of disinterest that teachers and schools bestow on their questions. Herbert Kohl's classic essay "I Won't Learn From You" is just one articulation of what every teacher knows, namely that curiosity can be withheld as a mark of disfavor, rejection, or antagonism and frequently represents an attempt at defense-defense of the self from accusations or fears of failure, defense of a culture belittled or attacked by arrogant and hostile content. ${ }^{24}$ In this way, too, curiosity and its absence is political, as attempts to pump children full of ideas unpalatable to them by virtue of their politics of superiority and arrogance, as well as by virtue of their hierarchical imposition, are met with the resistant Teflon wall of student boredom. Indeed, one of the marks of a good teacher is a wily ability to sneak through the cracks of student disengagement and arouse curiosity by creating subtle emotional alliances, while holding the school institution itself at arm's length. 


\section{Curiosity and Individualism}

The inherently anti-authoritarian nature of curiosity raises unexpected questions. If curiosity grows from a desire for self-reliance, we must confront a potential association of curiosity with not only righteous rebellion but individualism, and thereby crack open a can of worms. Hegemonic American culture gives a (lip service) valorization to a kind of individualism that sees persistent curiosity as a non-conformist expression of hardiness and strength of character, resisting hierarchy; think here of the errant yet admired boys of old children's literature, like Huck Finn or Tom Sawyer or Penrod. We place in contrast to this view the often older, sometimes Puritanical and sometimes medieval, understanding of curiosity as a willful, headstrong product of the sins of pride and disobedience. Although radicals don't gravitate towards the second, oppressive view that advocates a submissive and enforced incuriosity, neither is the first, boosterish capitalist celebration of individualism appealing. We must ask ourselves, does cherishing curiosity spring from an ahistorical (capitalist) and individualist idea of human nature? Are we actually promoting capitalist personality types in cultivating curiosity?

I think not. The reality of the individual in a capitalist society deeply contradicts capitalist ideology; capitalism vaunts individualism, yet systematically disables our ability to self-provision and creates historically unprecedented dependencies. ${ }^{25}$ Rather than believing the claim that under capitalism our individuality or our individual liberties are maximized, which they so clearly are not, perhaps we would do better to step back and consider how egalitarian societies have treated questions of individuality, conformity, and obedience. We might also imagine what our vision for the future entails. Anarchists and "libertarian socialists" (as Noam Chomsky often calls himself), particularly strongly in the global South, center the right to self-determination as not only compatible with but essential to socially just and egalitarian society. Indeed, "from each according to his or her ability and to each according to his or her need" holds great respect for the individual. In an egalitarian yet autonomist rather than institutionalist vision, many tensions over individualism dissolve, and support for (most forms of) individual curiosity becomes neither selfish nor ahistorical, but liberatory. ${ }^{26}$

\section{Co-opting and Subverting Curiosity}

What goes on in schools is part and parcel of the larger culture, and often is a mere reflection of it. If curiosity is doing so poorly in educational settings, what is happening to it in the wider world? First, we see the co-optation of curiosity for the purposes of power. Justin E. H. Smith writes that in our times, "...curiosity is co-opted by the state. And so begins the next chapter, the late modern chapter, of curiosity's history. Murals go up on the sides of public buildings depicting atoms, bridge builders, men in lab coats... Now the state grows jealous of the curiosity of individuals, seeking not so much to squelch it as simply to channel it for the state's own interests. Every competence must have a license, and every interest an official association." 27

In recent years, curiosity has also been quite explicitly tapped not just by political masters, but also by the corporate world. Harvard Business Review published a special spotlight section in its September-October issue in 2018 entitled "Why Curiosity Matters" to investigate "how leaders can nurture curiosity throughout their organizations and ensure that it translates to success." Outlining the benefits of curiosity-increased persistence and grit and less conflict in the workplace, among others - it discusses how to bolster curiosity by hiring managers who are curious and having "what if?" days where the "best" employee answers to those "what if?" questions were hung on the walls as a reward. (Shades of school, anyone?) ${ }^{28}$

Guillaume Paoli's aforementioned "falling rate of motivation" proposes that rather than a falling rate of profit as the Achilles heel of capitalism, an inexorably falling rate of motivation portends the end of our economic system. As bosses increasingly squeeze and control workers, workers become more and more listless and less and less motivated. As workers become 
less motivated, bosses then squeeze and control them even more in an attempt to increase productivity, creating a constant downward spiral. Paoli's solution is for us to jump to the end point by engaging immediately in demotivational training and putting an end to the capitalist misery. No surprise that bosses haven't cottoned to that idea and continue to search for ways to motivate their workers; harnessing curiosity seems to be a new frontier in their struggle.

Insidiously, in the world of institutional education, where curiosity has died a particularly unhappy death, curiosity of a certain, success-producing sort is now being trumpeted and posed alongside the educationally faddish "grit", as writers such as Paul Tough, in How Children Succeed: Grit, Curiosity, and the Hidden Power of Character, advise us how to promote curiosity as a way to remedy children's supposedly deficient characters and thereby avoid actually remedying social inequality, or at least unequal schooling. ${ }^{29}$ Similarly, the apparently irresistible capitalist urge towards transactional inducements has ironically led to the creation of an (extrinsic) award sponsored by the Wharton School of Business at the University of Pennsylvania entitled the "Reimagine Education--Cultivating Curiosity Award." The description announces that, "Successful projects will promote the value of curiosity as a tool for improving learning outcomes and/ or employability." The Center for Curiosity, under whose umbrella the award lives, "seeks to understand how curiosity might be defined and measured, so that it might be harnessed...." 30

As curiosity labors under the weight of its increasing co-optation on multiple fronts, we can look back at history and see that a refusal to be curious has been one form of a politics of resistance to the incorporation into The Establishment of previously embraced aspects of culture and schooling. Anti-intellectualism is a politics that has been engaged in not only by right-wing demagogues but also by the poor and the despised. Lawrence W. Levine remarked in Highbrow, Lowbrow that at the turn of the twentieth century Shakespeare, long popular across all socioeconomic strata in the U.S., was not abandoned by the lower classes but instead was appropriated (or we might say enclosed) by the elite, leaving the lower classes to feel that Shakespeare no longer belonged to them. ${ }^{31}$ When Shakespeare and Beethoven, or the engineering of bridges and science done in lab coats, are seized to become the clear cultural property of the elite, a lack of curiosity is engendered about literature and classical music and all those other realms of culture and knowledge newly anointed as highbrow and complicit in power. We observe here a historical confirmation that a happy or healthy curiosity requires some general sense of equality. A sense of inferiority leads not only to the withering of an ability to inquire, but also a resentment of the delineated realm of the socially superior and a refusal to be interested in it.

\section{Curiosity and Ignorance}

Looking past the notably skimpy academic investigation of curiosity, we can perhaps sidle up to the subject by drawing on the slightly richer study of ignorance for insight into incuriosity. Since curiosity is the personal and emotional expression of a desire to eliminate ignorance and is a means to accomplish that end, agnotology, as the philosophical study of ignorance, is closely allied to considerations of incuriosity. Incuriosity is both a cause of and a pathway to ignorance. Agnotologists describe, among many kinds of classification, three forms of ignorance: a native state of ignorance, a selective choice to be ignorant, and an active construction of ignorance. The two latter states of ignorance will be, must be, arrived at via a withholding or suppression of curiosity.

Just as agnotologists talk of willful ignorance, perhaps it is time to start talking about a willful incuriosity. And just as willful ignorance is not necessarily a negative, (as in a considered choice to not research the reprehensible), we must consider whether willful incuriosity is something that should necessarily be countered. When we encounter willful incuriosity, we must consider whether it may embody classism, racism, sexism or other relations of power, as those filled with arrogance refuse to learn about those they despise; this kind of withheld curiosity about something or someone can be a mark of social disdain, as well as a means to create the convenient 
ignorance that allows an evasion of responsibility by the powerful. But willful incuriosity may also embody a resistance to the hateful knowledge that classism, racism or sexism has produced, as the despised refuse to learn the knowledge produced by the despisers. Willful incuriosity should not be besieged as a matter of course. It may serve personally and politically useful functions, protecting both individual selves as well as communities from corrosive undermining and emotional damage. ${ }^{32}$

But regardless of the roots of willful disinterest, and despite its occasional effectiveness in creating an insulation from personal or cultural assaults, a refusal to be curious has a disturbing double edge, creating dysfunction and toxicity at the same time as it provides certain kinds of protection. While we might applaud students' strategy of mental and emotional absence from damaging classroom scenarios they are forced into, or adults' refusal to attend to toxic material, the success of that strategy of disengagement bleeds into the rest of life. It is unlikely that children could spend their school hours in a state of sulky disinterest or an adult could live workdays in a stolid emotional refusal, and yet emerge unscarred into a healthy and happy exploration and embrace of possibility after walking out of the doors of school or workplace at the end of a day. Habits of mind and emotion are sculpted through practice and repetition and are not so easily donned and shed.

\section{| The Prospects for Curiosity}

Our curiosity erodes thanks to educational violence, due to the pathologies generated by social hierarchy, as a result of co-optation by bosses, and through willful disinterest. It is also under assault by time poverty and speed. Several years ago in this journal, advocating a rejection of the pace of modern capitalism, Jeremy Hunsinger wrote, "Without the ability to change the environment or our situatedness in relation to our strategic speed, we are left with the only thing left to change, ourselves." 33 Curiosity may be the canary in the coal mine, the first part of our selves that changes, that suffocates when we are overwhelmed by warp peed.

Deep curiosity requires attention, presence, and alertness. A meaningfully alive public sphere requires a curiosity about and an active perception and acknowledgment of other humans. But we live in a world of disappearing attention, a failure to truly attend, which, after all, requires patience and waiting. Attention and curiosity, as opposites of apathy, in turn, require hope. Curiosity implies a sense of personal efficacy and possibility, a belief that one's curiosity might be fulfilled by one's own actions, as well as a sense of the future. The sense of powerlessness and precarity that dominate our mood today directly displace and preempt curiosity, creating instead that dominant effect of contemporary capitalism: anxiety. To occupy our anxious minds, which cannot attend, we replace true attention with aimless or idle distraction, both of which can, strangely enough, be encompassed within the meanings of the English language term "curiosity." "34

On my 30 minute walk home from work on the day I had my epiphany, I saw: babies in strollers babbling and waving while their parent stared at a phone, dogs sniffing and exploring while their people stared at phones, cops in parked patrol cars flicking through phones, construction workers on lunch break staring at phones, a salon with a woman getting her nails painted and a woman getting her head massaged while each gazed at phones, and people with earbuds walking vacantly past a homeless man on the sidewalk. The night before I had stared in incredulity at a college student sitting at the edge of a stage in an intimate theater, swiping aimlessly through his glowing phone screen while one-foot away actors raged. (Presumably, this young man's behavior was the result of some combination of a lifetime of institutionalization in schools and current resentment at having to attend the theater as some kind of course requirement, and who knows, maybe I'd have done the same in his shoes.) Universally, undemanding screens entertained an aimless "curiosity" that stood in for the babies, dogs, public scenes, physical contact, and adult humans who would otherwise have required our attention. 
The class session I left those few months ago, feeling despondent about my usefulness as a teacher, was one in which students idly scrolled through their handheld devices as a few of us held a conversation about climate change and the ecological state of the planet. Maybe they just wanted to hide from the terror of the topic, but they'd had the same reaction another day when we'd played with plants I had picked on my way into school, using the urban weed nature guides I'd brought to identify them. Was these students' apathy the result of a violent extinguishing of their curiosity by educational institutions, a sullen, resistant refusal to be curious in a college program they didn't really want to be in, a total failure of hope, a reactionary resentment of the politics of the course, or an expression of their incredible stress levels?

We'll all have to figure out such scenarios if we want to reach across the communicative chasms created by compulsion, resistance, arrogance, anger, despair, and anxiety. What my epiphany told me is that the very first thing we need to do, if we are going to build a joyful militancy, is to recognize that curiosity is not only an intellectual and academic concern. It is also an emotional, moral, and political state in desperate need of cultivation and tender loving care. 


\section{Endnotes}

1. John Dewey, Democracy and Education (New York: The Free Press, 1944), 209.

2. The Institute for Precarious Consciousness, "Anxiety, affective struggle, and precarity consciousness-raising", Interface: a journal for and about social movements 6, No. 2 (2014): $271-300$.

3. For a comprehensive, scientifically oriented review of how living amid inequality translates to mental states and emotions see the best-selling book The Spirit Level: Why Greater Equality Makes Societies Stronger by epidemiologists Richard Wilkinson and Kate Pickett (New York: Bloomsbury Press, 2010) and their follow up The Inner Level: How More Equal Societies Reduce Stress, Restore Sanity and Improve Everyone's Well-being (New York: Penguin Press, 2019).

4. The brand-new volume Curiosity Studies: A New Ecology of Knowledge (Minneapolis: University of Minnesota Press, 2020), edited by Perry Zurn and Arjun Shankar, and announcing itself as the first Anglophone cross-disciplinary consideration of curiosity, features a review of the literature in its introduction by the editors.

5. Guillaume Paoli, Demotivational Training (Berkeley: Cruel Hospice, 2013).

6. Cynthia Enloe, The Curious Feminist: Searching for Women in an Age of Empire (Berkeley: U. of California Press, 2004).

7. The work of philosopher of science Sandra Harding provides a comprehensible yet sophisticated survey of standpoint theory and the social construction of knowledge.

8. Upton Sinclair, I, Candidate for Governor: And How I Got Licked (Berkeley: University of California Press, 1994 [1935]), 109.

9. Robert N. Proctor and Londa Schiebinger, eds., Agnotology: The Making and Unmaking of Ignorance (Stanford: Stanford University Press, 2008) is considered the foundation of the field.

10. Perry Zurn and Arjun Shankar, "Introduction: What is Curiosity Studies," in Curiosity Studies: A New Ecology of Knowledge, ed. Perry Zurn and Arjun Shankar (Minneapolis: University of Minnesota Press, 2020), xi-xxx.

11. Carl Goldberg, "Curiosity as an Agent of Conscience," Pastoral Psychology 52, No. 4 (2004): 329-338.

12. Nancy Leonard and Michael Harvey, "The trait of curiosity as a predictor of emotional intelligence," Journal of Applied Social Psychology 37, No. 8 (2007): 1914-1929

13. Michel Foucault, "The Masked Philosopher," in Michel Foucault: Politics, Philosophy, Culture, Interviews and Other Writings 1977-1984, ed. L. D. Kritzman (London: Routledge, 1988) 1998-99. Used as an opening epigraph in Curiosity and Method: Ten Years of Cabinet Magazine (Brooklyn: Cabinet Books, 2012).

14. Wilfred Hamlin, "What Progressive Education Means at Goddard," 1990. In possession of the author.

15. Barbara Tizard and Martin Hughes, Young Children Learning (Cambridge, Mass.: Harvard University Press, 1985), 230.

16. Erica Christakis, "The New Preschool Is Crushing Kids," The Atlantic 137, No. 1(2016), 17-20. Alfie Kohn, No Contest: The Case Against Competition (New York: Houghton Mifflin, 1992), by an educational theorist, does not address curiosity explicitly but builds a thorough case that competition and the emotions it provokes reduce creativity, a closely allied state.

17. Cited in Tyson E. Lewis, "Teaching with Pensive Images: Rethinking Curiosity in Paulo Freire's Pedagogy of the Oppressed," The Journal of Aesthetic Education 46, No. 1 
(2012): 28 .

18. H.I. Day, "Curiosity and the Interested Explorer,” NSPI Journal May 1982, 19.

19. Susan L. Engel, The Hungry Mind: The Origins of Curiosity in Childhood (Cambridge, Mass: Harvard University Press, 2015).

20. Susan Engel, "Why Should This Be So?: The Waxing and Waning of Children's Curiosity," in Curiosity Studies: A New Ecology of Knowledge, ed. Perry Zurn and Arjun Shankar (Minneapolis: University of Minnesota Press, 2020), 75-90.

21. Martin Carnoy's Education as Cultural Imperialism (New York, David McKay Co.: 1974) and Paul Willis' Learning to Labor: How Working Class Kids Get Working Class Jobs (New York: Columbia University Press, 1981) are but two examples of earlier leftist analyses of schooling that posited that socializing children to capitalism was the very reason for public education. Unfortunately, radicals in recent years have hesitated to critique schooling, perhaps fearing to strengthen rightwing attacks on public education. I believe this is a huge mistake. See my piece "Reclaiming the Radical Critique of Education" at https:// truthout.org/articles/reclaiming-the-radicalcritique-of-education/

22. Ivan Illich, "Disabling Professions," in Disabling Professions, Illich et al (London: Marion Boyars, 1977), 33.

23. Matthew Crawford, Shop Class as Soul Craft: An Inquiry Into the Value of Work (New York: 2010), 68.

24. Herbert Kohl, I Won't Learn From You and Other Essays in Creative Maladjustment (New York: The New Press, 1995).

25. Michael Perelman, The Invention of Capitalism: Classical Political Economy and the Secret History of Primitive Accumulation (Durham: Duke University Press, 2000) emphasizes that the institution of private property was mostly about excluding workers from the means of subsistence and thereby preventing self-provisioning, creating a dependence on the social division of labor, wage labor, and commodities.

26. For an elaborated vision of learning that follows in Illich's footsteps, rejecting both capitalist individualism as well as capitalist conformity, see Gustavo Esteva and Madhu Suri Prakash, Escaping Education: Learning as Living Within Grassroots Cultures (New York: Peter Lang, 1998). The book opens with an epigraph from the essay "Self-Reliance" by Ralph Waldo Emerson. Also see the work of Shikshantar: The People's Insittute for Rethinking Education and Development at http://shikshantar.org/home and The Swaraj Foundation at swaraj.org, which advocates that the self-rule that the Gandhian concept of swaraj refers to is not merely Indian decolonization, but also necessarily includes "self-respect, self-responsibility, and capacities for self-realization.”

27. Justin E. H. Smith, "Curiosity”, in Curiosity and Method: Ten Years of Cabinet Magazine (Brooklyn: Cabinet Books, 2012) 482.

28. See https://hbr.org/2018/09/curiosity

31. Paul Tough, How Children Succeed: Grit, Curiosity, and the Hidden Power of Character (Boston: Houghton Mifflin Harcourt, 2012).

30. See https://www.reimagine-education. com/cultivating-curiosity-award/

31. Lawrence W. Levine, "Shakespeare in America," in Highbrow, Lowbrow: The Emergence of Cultural Hierarchy in America (Cambridge Mass.: Harvard University Press, 1988).

32. For more on the politics of an unquestioning celebration of curiosity, see Marianna Papastephanou, “The 'Lifeblood' of Science and Its Politics: Interrogating Epistemic Curiosity as an Educational Aim," Education Sciences 6, No. 1, article 1 (2016). 
33. Jeremy Hunsinger, "Against Speed Cosmopolitanism towards a slow university," Fast Capitalism 10, No. 1 (2013). http://www. uta.edu/huma/agger/fastcapitalism/10_1/ hunsinger10_1.html

34. For more on the role of emotions, and anxiety in particular, in curiosity, see pages 3136 passim in Susan Engel's Hungry Mind. 
